Revista Educação e Políticas em Debate - v.10, n.1, p. 469-481, jan./abr. 2021 - ISSN 2238-8346

\title{
A Base Nacional Comum Curricular e as formas de subjetivação do professor de Matemática
}

The National Curricular Common Basis and the forms of subjectivation of the Mathematics teacher

La Base Nacional Comum Curricular et les formes de subjectivation du professeur de mathématiques

Jaíne Telles Quevedo ${ }^{1}$

Universidade Federal de Pelotas

Letiane Oliveira da Fonseca ${ }^{2}$

Universidade Federal de pelotas

Márcia Souza da Fonseca ${ }^{3}$

Universidade Federal de Pelotas

Mônica Roxo Correa ${ }^{4}$

Universidade Federal de Pelotas

Resumo: $\mathrm{O}$ artigo propõe um debate acerca das proposições da Base Nacional Comum Curricular (BNCC) e os seus impactos na formação de professores que ensinam Matemática. Para tanto, destaca-se como problemática: "Qual perfil de professor que ensina Matemática no ensino fundamental é desejado pela BNCC?”. A análise discursiva foi utilizada na compreensão das relações de poder que emergem do discurso da Base. No que concerne ao currículo, ao conhecimento escolar e às subjetivações, Apple (2001 e 2006) e Silva (1999) subsidiaram as discussões, possibilitando a percepção de que a BNCC, como documento norteador, sugere a Matemática como uma ciência humana produzida por diferentes grupos sociais - contudo, apresenta um discurso hegemônico, priorizando certos saberes e competências.

Palavras-chave: Política educacional. Currículo e poder. Formação Matemática.

Abstract: The article proposes a debate concerning the propositions of the National Curricular Common Basis (NCCB) and its impacts in the training of teachers who teach mathematics. In order to do so, the main question is: "Which profile of Math teacher at Elementary Schools is expected by the NCCB?". The discourse analysis was used in the understanding of relations of power that arise from the Basis discourse. Concerning the curriculum, school knowledge and subjectivations, Apple (2001 e 2006) and Silva (1999)

\footnotetext{
1 Acadêmica do Mestrado em Educação Matemática da Universidade Federal de Pelotas. Professora alfabetizadora na Escola de Ensino Fundamental Castro Alves. E-mail: quevedojaine@gmail.com. Lattes http://lattes.cnpq.br/1274767143646792. ORCID: https://orcid.org/0000-0002-1865-6601.

${ }^{2}$ Mestra em Educação Matemática pela Universidade Federal de Pelotas. Professora de Matemática na rede municipal de Pelotas. E-mail: letianefonseca@yahoo.com.br. Lattes: http://lattes.cnpq.br/2534457475282190. ORCID: https://orcid.org/0000-0002-6410-9895.

${ }^{3}$ Doutora em Educação pela Pontifícia Universidade Católica do Rio Grande do Sul. Docente do Instituto Física e Matemática da Universidade Federal de Pelotas. E-mail: mszfonseca@gmail.com. Lattes: http://lattes.cnpq.br/7950804967345359. ORCID: http://orcid.org/o000-0001-9215-4370.

${ }^{4}$ Especialista em Orientação Educacional pela Faculdade Dom Bosco. Professora de Educação Infantil na rede municipal de Pelotas. E-mail: moni.roxo@hotmail.com. Lattes: http://lattes.cnpq.br/6783851358328807. ORCID: https://orcid.org/0000-0003-1399-406X.
} 
Revista Educação e Políticas em Debate - v.10, n.1, p. 469-481, jan./abr. 2021 - ISSN 2238-8346

supported the discussions, enabling the perception that the $\mathrm{NCCB}$, as a guiding document, suggest Mathematics as a human science - produced by different social groups. However, it presents a hegemonic discourse, prioritizing certain knowledge and skills.

Keywords: Educational policy. Curriculum and power. Mathematical training.

Résumé: Cet article propose un débat sur les propositions de la Base Nacional Comum Curricular (Base Nationale Commune des Programmes d'Enseignement, en français) et leurs impacts pour la formation des professeurs de mathématiques. Dans ce but, la problématique suivante est soulignée: "Quel profil de professeur qui enseigne les Mathématiques au Ensino Fundamental est souhaitable par la BNCC?». L'analyse discursive a été employée pour la compréhension des relations de pouvoir qui ressort du discours de la Base. En ce qui concerne les programmes d'enseignement, la connaissance scolaire et les subjectivations, Apple $(2001$; 2006) et Silva (1999) constituaient la base théorique des discussions de ce travail, en rendant possible la perception selon laquelle la BNCC, en tant que document d'orientation, suggère les mathématiques comme une Science Humaine - produite par des différents groupes sociaux ; par contre, le document présente aussi un discours hégémonique, qui donne priorité à certains savoirs et compétences.

Mots-clés: Politique éducative. Programmes d'enseignement et pouvoir. Formation en mathématiques.

Enviado em: 24 de maio de 2020 Aceito em: 23 de novembro de 2020

\section{Introdução}

O documento oficial da Base Nacional Comum Curricular (BNCC) prevê um currículo único prescrito para a Educação Básica no país. A pertinência e a atualidade do tema justificam as discussões a respeito da BNCC e das relações de poder que permeiam o seu discurso. Vale evidenciar que a BNCC propõe a definição de um conjunto de aprendizagens essenciais que deverão ser adquiridas pelos alunos, pois, segundo esse documento, somente dessa forma, todos os alunos terão os seus direitos de aprendizagem e o seu desenvolvimento assegurado (BRASIL, 2017).

Nesse sentido, o discurso disseminado pela BNCC defende a ideia de um currículo homogeneizador, implantado em todas as instituições escolares do país, capaz de assegurar, em âmbito nacional, uma educação de qualidade para todos e todas, com base em princípios de "igualdade, diversidade e equidade" (BRASIL, 2017, p. 15).

Salienta-se que, em controvérsia ao seu discurso de respeito à diversidade, o mesmo documento trata sobre competências e habilidades que deverão ser adquiridas pelos estudantes, em tempos e em níveis estabelecidos previamente. Macedo (2016) evidencia esse antagonismo estabelecido entre a ideia de aprendizagem e de avaliação por 
Revista Educação e Políticas em Debate - v.10, n.1, p. 469-481, jan./abr. 2021 - ISSN 2238-8346 competências (pré-estabelecidas) e o compromisso com a igualdade, a diversidade e a equidade apresentado pelo discurso da BNCC.

Em relação a essa busca por padronização, Macedo (2016) adverte que nas escolas não haverá mais lugar para o diferente, um único currículo terá o controle sobre o, até então, "sujo" imprevisível que afronta o espaço escolar.

Causa estranhamento que a Base Nacional Comum Curricular, como política pública educacional pautada no comprometimento com a igualdade, a diversidade e a equidade, oriente a implementação de um currículo que pré-determina “o tempo certo de aprender" e que acaba por legitimar um sistema de avaliações nacionais.

Para Appel (2001), um “[ [...] currículo nacional numa época de hegemonia neoconservadora e neoliberal é uma fórmula para aquilo que simplesmente sem cerimônia denomino por 'apartheid educativo” (2001, p. 28-29). Apple e Beane (2001) ressaltaram que, apesar de a implementação de um currículo comum ofertar a possibilidade de um debate democrático, em âmbito nacional, acerca do que é considerado conhecimento escolar, há uma perigosa soberania das ideologias das classes dominantes na hora de pensar políticas curriculares e, por consequência, currículos de formação.

Ainda nesse sentindo, não são somente os currículos ${ }^{5}$ das escolas que se pretende controlar, posto que a formação do professorado - aqueles que deveriam ser responsáveis por construir seus currículos - também sofrerá os reflexos do discurso da base. A formação dos docentes terá de abarcar os princípios estabelecidos pela BNCC, visto que, segundo a terceira (e oficial) versão do documento:

Referência nacional para a formulação dos currículos dos sistemas e das redes escolares dos Estados, do Distrito Federal e dos Municípios e das propostas pedagógicas das instituições escolares, a BNCC integra a política nacional da Educação Básica e vai contribuir para o alinhamento de outras políticas e ações, em âmbito federal, estadual e municipal, referentes à formação de professores, à avaliação, à elaboração de conteúdos educacionais e aos critérios para a oferta de infraestrutura adequada para o pleno desenvolvimento da educação (BRASIL, 2017, p. 8, grifos nossos).

É preciso ressaltar que, como o campo do currículo é permeado por relações de poder e, também, de lutas sociais, há uma evidente movimentação de especialistas da área da Educação que, preocupados com os possíveis retrocessos culminados por um sistema educacional diretamente ligado à avaliação por competências e pela busca por hegemonia, fomentam debates sobre a BNCC, dentro e fora das academias.

\footnotetext{
${ }^{5}$ Utiliza-se a palavra no plural para evidenciar a pluralidade de currículos constituídos em todos os espaços, por diferentes agentes sociais — frente à proposta da BNCC de único e padrão currículo base.
} 
Revista Educação e Políticas em Debate - v.10, n.1, p. 469-481, jan./abr. 2021 - ISSN 2238-8346

Assim, cumpre destacar o importante movimento "ANPEd e a BNCC: luta, resistência e negação", promovido (desde 2015) pela Associação Nacional de Pós-Graduação e Pesquisa em Educação, entidade com grande reconhecimento dentro do cenário das pesquisas em Educação. Segundo sua homepage, a ANPEd (2020) vem

produzindo um conjunto de posicionamentos críticos acerca da proposição de uma Base Nacional Comum Curricular. São elementos presentes nesta crítica tanto a metodologia de elaboração que privilegia especialistas e subalterniza o diálogo com as comunidades escolares quanto suas evidentes implicações nos processos de avaliação, de ensino e aprendizagem, na homogeneização das matrizes curriculares, na formação de professores e autonomia das escolas que se fragilizam com a lógica de centralização que a BNCC instaura na educação escolar.

Esses debates promovidos pela ANPEd vêm ocorrendo desde 2015, quando o Ministério da Educação lançou os primeiros esboços do que seria o documento norteador da educação básica brasileira (implementado anos depois). Pelo exposto, é possível perceber que vários profissionais da área da Educação buscaram e continuam buscando por espaços para discutir a respeito das implicações de um currículo comum instituído nas escolas e que afeta, diretamente, na formação dos futuros professores.

Faz-se necessário observar que o currículo aqui é compreendido como um documento regulador, que desempenha o papel de selecionar e de ordenar os saberes considerados legítimos. No mesmo passo, Sacristán (2013) evidencia que, desde a sua origem, o currículo comporta-se como um sistema de regulamentação capaz de "estruturar a escolarização, a vida nos centros educacionais e as práticas pedagógicas, pois dispõe, transmite e impõe regras, normas e uma ordem que são determinantes” (2013, p. 20).

Dessa maneira, considerando a formação inicial (licenciatura) e o atual campo de formação em que estão inseridas as autoras deste artigo - Mestrado Acadêmico em Educação Matemática ${ }^{6}$ - as pesquisadoras sentiram a necessidade de refletir acerca das subjetivações impostas pelo discurso da BNCC na formação dos futuros professores de Matemática que atuarão no ensino fundamental - lembrando que a versão oficial da Base já está em vigor desde o dia 15 de dezembro de 2017 e que norteia tanto a formação ofertada na educação básica, quanto a formação docente dos cursos de licenciaturas.

Pelo já exposto, pretende-se, com este artigo, problematizar "Qual perfil de professor que ensina Matemática no ensino fundamental é desejado pela BNCC?”.

Cabe destacar as subjetivações impostas pelos currículos de formação à identidade do professorado, haja vista que o currículo é um campo marcado por tensões, conflitos e

${ }^{6}$ O Programa de Pós-graduação em Educação Matemática da Universidade Federal de Pelotas (PPGEMAT-UFPel) alicerça-se nos paradigmas que permeiam o ensino e a aprendizagem de Matemática, dentro e fora do contexto escolar. 
Revista Educação e Políticas em Debate - v.10, n.1, p. 469-481, jan./abr. 2021 - ISSN 2238-8346 discursos de poder (SILVA, 1999). Com base nesse ponto, o artigo objetiva discorrer acerca dos discursos normativos enunciados pela BNCC e as suas implicações na formação inicial do professor que ensina Matemática no ensino fundamental da educação básica.

\section{Produção e exclusão de identidades}

A escola pública é um espaço de luta e de resistência, de busca por educação de qualidade, ainda que com possibilidades limitadas pelo descaso do poder público. Estar na escola e permanecer nela, bem como os processos (distintos) de ensinar e aprender, são partes de um mecanismo de resistência. Apple (2006) afirma que ser educador é estar envolvido com um ato político; Freire (1997) também se baseava na mesma premissa, ao defender o ensino como exemplo de ato político.

Para complementar o exposto, é preciso dizer que ser educador e ser estudante, em tempos de neoliberalismo, é um ato de resistência política, digno daqueles que buscam ser cidadãos livres através da educação.

Contrapondo a ideia de educação para formar cidadãos livres, tem-se o cenário de uma escola como máquina de preparação para o mercado de trabalho em sociedade. Cabe pensar, também, que uma sociedade é pautada sob relações de poder e de perpetuação do controle sobre determinado grupo. Busca-se utilizar ferramentas de controle para alcançar esse objetivo, e nada melhor do que o espaço escolar para a construção de uma sociedade hierarquicamente estruturada e desigual; por meio das políticas curriculares, pelas quais se espera transformar a sociedade, pois, como evidencia Silva (1999), currículos formam identidades:

As políticas curriculares interpelam indivíduos nos diferentes níveis
institucionais aos quais se dirigem, atribuindo-lhes ações e papéis
específicos. Burocratas, delegados, supervisores, diretores, professores. [...].
As políticas curriculares movimentam, enfim, toda uma indústria
culturalmente montada em torno da escola e da educação (p. 11).

Ainda que as políticas curriculares atendam, em parte, as demandas de grupos sociais que representam as classes sociais mais desfavorecidas, que, por sua vez, lutam em espaços de resistência para serem ouvidos e visibilizados, as Políticas Curriculares de âmbito nacional acabam por reverberar a internalização de normas e valores que objetivam assegurar os interesses de certos grupos dominante (APPLE, 2001).

O currículo torna-se, assim, uma ferramenta de poder, que produz identidades de acordo com o seu interesse, ou melhor, de acordo com o interesse do discurso perpetuado pelos grupos que produzem o currículo. Ainda em Silva (1999), tem-se que 
Revista Educação e Políticas em Debate - v.10, n.1, p. 469-481, jan./abr. 2021 - ISSN 2238-8346

O currículo também fabrica objetos de que fala: saberes, competências, sucesso, fracasso. [...] produz os sujeitos aos quais fala, os indivíduos que interpela. O currículo estabelece diferenças, constrói hierarquias, produz identidades (SILVA, 1999, p. 12).

Tendo ciência da importância do currículo na constituição da sociedade e de suas relações de poder, interessa analisar e discutir sobre o discurso propalado pela nova Base Nacional Comum Curricular (BNCC) proposta e aprovada pelo governo, desde 2017.

Mas que identidades interessam ser produzidas por esse currículo comum instituído em todo o território nacional? Esse questionamento alavanca as próximas discussões tecidas no decorrer deste artigo.

Destaca-se, na sequência, um trecho da Base Nacional Comum Curricular, que trata sobre o comprometimento com a promoção de uma educação integral e voltada para o respeito às diferenças:

\begin{abstract}
A BNCC expressa o compromisso do Estado Brasileiro com a promoção de uma educação integral voltada ao acolhimento, reconhecimento e desenvolvimento pleno de todos os estudantes, com respeito às diferenças e enfrentamento à discriminação e ao preconceito. Assim, para cada uma das redes de ensino e das instituições escolares, este será um documento valioso tanto para adequar ou construir seus currículos como para reafirmar o compromisso de todos com a redução das desigualdades educacionais no Brasil e a promoção da equidade e da qualidade das aprendizagens dos estudantes brasileiros (BRASIL, 2017, p. 5, grifos nossos).
\end{abstract}

Ainda no texto introdutório da BNCC, tem-se um discurso que prevê a igualdade de possibilidades de ensino para que todos ingressem e permaneçam na escola. Na página dez desse documento, é possível notar o discurso que mostra o poder que o currículo e a base têm na transformação da sociedade e de seus sujeitos. Também nesse trecho do documento, é apresentada a definição de competência, conceito fundamental e que deve ser problematizado nas discussões acerca da BNCC. O documento salienta:

Competência é definida como a mobilização de conhecimentos (conceitos e procedimentos), habilidades (práticas, cognitivas e socioemocionais), atitudes e valores para resolver demandas complexas da vida cotidiana, do pleno exercício da cidadania e do mundo do trabalho (BRASIL, 2017, p. 8).

Ao final da introdução, abre-se margem para a diferenciação dos currículos formadores, quando o documento afirma que as competências e as diretrizes do ensino são comuns, porém, os currículos não seguem essa estruturação.

Assim sendo, o Ministério da Educação propõe uma base comum curricular ao país com a ideia de equidade de ensino e de possibilidades aos estudantes, no entanto, deixa uma 
Revista Educação e Políticas em Debate - v.10, n.1, p. 469-481, jan./abr. 2021 - ISSN 2238-8346 brecha em seu documento, dando poder às instituições escolares para que estas utilizem as competências e as diretrizes de forma que o seu currículo possa se diferenciar dos demais.

Ao refletir sobre a complexidade da implementação de "brechas" nos currículos constituídos para cada escola, pode-se pensar na importância de se dialogar sobre resistência a uma base homogeneizadora antagônica, a ideia de qualidade de ensino e de respeito à diferença, posto que uma instituição com agentes (muitas vezes) já subjetivados pela ideia de salvação oferecida pela Base, não reconhecerá a importância de pensar nas singularidades de cada sujeito e instituição escolar. Em resumo, ao aceitarem a ideia de um currículo comum como a solução de todos os problemas da educação, não haverá empenho por produzir currículos que respeitem as particularidades regionais.

É possível perceber o quão válido são essas problematizações? E o quanto essa ideia de salvação e de remediação dos problemas da educação pode ser incutida já na formação desses sujeitos? Questionamentos como esses impulsionam algumas das reflexões aqui tecidas sobre os processos de subjetivação impostos pelos currículos.

Discutir a respeito dessas formas de subjetivação é necessário, na medida que se compreende que esses processos devem ser desnaturalizados na sociedade. É importante compreender, por exemplo, quais são os interesses que perpassam a busca pela padronização de identidades, por meio de um currículo universalizante. Quais são as identidades almejadas por esses currículos? E quais serão subalternizadas nesse processo?

Nota-se que o currículo é capaz de produzir exclusões alicerçadas em uma sociedade estruturada em relações de poder e subalternizações na qual os que possuem mais domínio determinam o que é - cientificamente, culturalmente e produtivamente — válido à sociedade. Novamente, reporta-se à Silva (1999) quando afirma que

o currículo, tal como a cultura, é uma zona de produtividade. Essa produtividade, entretanto, não pode ser desvinculada do caráter social dos processos e das práticas de significação. Cultura e currículo são, sobretudo, relações sociais (SILVA, 1999, p. 21).

O evidenciado pelo autor reafirma a ideia de que currículo não pode ser concebido como algo neutro e desvinculado das questões de poder que permeiam a sociedade, pois essa desvinculação acarretaria o ocultamento de inúmeras tramas sociais, que buscam selecionar o padrão de indivíduo desejado pelos grupos sociais dominantes - grupos privilegiados pelo poder de selecionar o que deve ou o que não fazer parte dos currículos. 
Revista Educação e Políticas em Debate - v.10, n.1, p. 469-481, jan./abr. 2021 - ISSN 2238-8346

\section{Base, currículo e formas de subjetivação}

A Base Nacional Comum Curricular apresenta, no título, a expressão "Educação é a base", um enunciado que evidencia as intenções daqueles que tratam a ideia de uma base como algo que é essencial/indispensável ao desenvolvimento humano. Nesse sentido, as questões que restam são: que formas de desenvolvimento se deseja por meio dessa Base Comum e a quem esse desenvolvimento interessa?

A base propõe um currículo homogeneizador que chega aos professores e aos alunos, que estão se adequando aos poucos a essa nova formulação curricular, por meio das instituições escolares e de agentes externos - políticas públicas e curriculares - com o objetivo de constituir identidades sociais e de orientar práticas escolares - definindo qual o saber/conhecimento é válido e quem são as pessoas que se espera formar com esse documento.

Esse currículo comum almeja formar pessoas, cidadãos, independentemente de idade, classe social; seu objetivo é construir a ideia de ser social e "bom" profissional, esperado e bem-sucedido na sociedade.

A Base Nacional Comum Curricular para a Educação Infantil e o Ensino Fundamental é composta por 472 páginas. No item de apresentação do documento, é possível encontrar expressões direcionadoras, enunciados motivadores que destacam, sobretudo, a ideia de assegurar uma educação de qualidade em nível nacional. Contudo, pode-se notar que o mesmo documento carrega consigo conceitos excludentes e autoritários, que não consideram as diferenças dos sujeitos.

Os discursos que imperam na BNCC estabelecem seu caráter homogeneizador e sua busca por controle social - busca-se formar sujeitos "perfeitos" e compatíveis com o ideal de sociedade almejado por uma minoria com poder de definir coisas e pessoas. Conforme relata Silva (1999, p. 85), “a diversidade cultural é, aqui, fabricada por um dos mais poderosos instrumentos de homogeneização", salientando que a busca da padronização é que produz a diferença do(a) outro(a), algo que precisa ser subjetivado em prol de uma sociedade melhor e mais desenvolvida.

Para alcançar tal nível de desenvolvimento, é preciso formar pessoas capazes e habilidosas, prontas para o mercado que as espera, que, se bem preparadas, auxiliarão nessa caminhada em busca do desenvolvimento do país.

Com isso, passa a ser responsabilidade social das escolas, dos professores, dos alunos e de seus familiares, e de toda a comunidades escolar contribuir para esse desenvolvimento global. E qual o papel do Estado nessa progressão? Cabe-lhe pensar o currículo nacional que 
Revista Educação e Políticas em Debate - v.10, n.1, p. 469-481, jan./abr. 2021 - ISSN 2238-8346 assegurará o direito de aprendizagem dos sujeitos; aos demais agentes escolares (já citados anteriormente) fica a responsabilidade de gerar bons frutos desse currículo promissor.

Ao analisar as dez competências gerais descritas no documento (p. 9) sobre as aprendizagens ditas essenciais, é possível destacar como tais orientações vão subjetivando o profissional da área de Educação. Algumas palavras-chave foram salientadas, pois evidenciam as subjetivações impostas ao professorado.

Destaca-se, assim, a utilização dos verbos em cada início da frase, tais como "valorizar", "exercitar", "agir" e "utilizar". Como se anunciasse a ideia de que, na atual e cotidiana prática de professores e professoras, essas ações já não existissem e, portanto, necessitassem de um guia para mediar seu fazer pedagógico.

Entendendo que a realidade - e as verdades que se produzem sobre ela - é uma construção discursiva e não um dado a priori, aqui se pretende a universalização da realidade. O sujeito que emerge desse discurso é essencialmente individualizado e, sobre ele, determinam-se comportamentos ideais a uma produção também ideal. Desse sujeito é exigida atitude favorável para a aprendizagem de Matemática como confiança, perseverança, esforço, interesse e disciplina. Além disso, esse sujeito precisa conhecer estratégias para calcular e generalizar resultados (FONSECA; RIOS, 2018).

Sem enganos, essa forma de racionalidade desenha a concepção do currículo e os modelos de estudante/professor desejado, que devem ser conduzidos à reforma educativa e à reforma de si mesmo como indivíduo (Ibid., 2018).

Evidenciam-se, ainda, nas competências, as expressões "continuar aprendendo", "curiosidade intelectual", "criar tecnologias" e "mundo do trabalho", que mostram a importância dada pela base à preparação para o mercado de trabalho globalizado e tecnológico.

Tais discursos remetem ao desenvolvimento de competências e de habilidades dos alunos, todavia, não descrevem de forma explícita o papel do professor e a sua produção de conhecimento aliada à prática desenvolvida em sala de aula.

Assim sendo, o discurso da base dá a entender que aos estudantes fica a responsabilidade de aprender a aprender, e aos professores cabe a missão de apresentar em sala de aula os componentes daquele currículo - já prontos e pré-estabelecidos por quem "entende” do assunto. Dessa forma, a nenhum deles resta a responsabilidade intelectual de pensar e/ou criar currículos.

Como aponta Vieira e Hypolito (2013):

Nessa perspectiva, o lugar da cultura, o espaço da história, vem sendo substituído por concepções cognitivistas e quantitativistas, que instituem significados universalizantes, a-históricos, talvez científicos, certamente vazios. Não por acaso o discurso educacional prevalente é aquele que partilha enunciados de certa psicologia do desenvolvimento e que valoriza 
Revista Educação e Políticas em Debate - v.10, n.1, p. 469-481, jan./abr. 2021 - ISSN 2238-8346 conceitos tais como flexibilidade, adaptação, criatividade, competências todos reforçando a ideia do "aprender a aprender", como se pudesse haver educação sem uma matéria sobre qual se exerça trabalho. (p. 128)

Aqui se anuncia uma redução do processo educacional à ideia de aprendizagem e de ensino, agora relacionada a processos cognitivos, excluindo o espaço da diferença na educação e nos currículos.

\section{A formação matemática e as formas de subjetivação impostas pela BNCC}

Ao lançar o olhar analítico para o discurso da BNCC referente à formação docente e, mais especificamente, à formação de professores de Matemática, faz-se necessário refletir sobre as especificidades da área de Matemática apresentada pelo documento.

Sendo assim, esta escrita encaminha-se para a análise do discurso anunciado pela Base Nacional Comum Curricular na área de Matemática e seus possíveis impactos na formação dos professores que a ensinarão no ensino fundamental.

Na leitura do documento, nota-se que a BNCC coloca essa área do ensino (Matemática) como uma ciência humana, não a considerando mais exata. No entanto, o caráter humanizado dessa ciência aparece somente ao final das competências apresentadas pela base - ao propor que a Matemática deve ser trabalhada a favor da sociedade e da resolução de problemas sociais, de modo que o estudante tenha capacidade de análise crítica frente aos dados que terá acesso.

O discurso enunciado pela base menciona que alguns conteúdos matemáticos ligados à Aritmética, Álgebra, Geometria, Estatística e Probabilidade devem ser desenvolvidos para auxiliar nas observações empíricas do mundo real e nas representações, que servirão para a aquisição da capacidade - especialmente no ensino fundamental — de utilizar a Matemática para a resolução de problemas sociais. Segundo o documento, o ensino fundamental deve ter o compromisso com o letramento matemático, que, por sua vez, é essencial para que o educando reconheça como os conhecimentos matemáticos são fundamentais para a compreensão e a atuação na vida cotidiana (BRASIL, 2017).

$\mathrm{Na}$ realidade, tem-se que o compromisso de desenvolvimento cognitivo e a progressão dos conhecimentos ditos essenciais por parte do aluno recai sobre o professor que deverá ser responsável pela aquisição das aprendizagens do estudante, no tempo certo e pré-estabelecido pela base curricular.

Esse processo de responsabilização vai constituindo um profissional com excesso de tarefas e de obrigações, além das formas de subjetivação propostas pela ideia de culpa e de 
Revista Educação e Políticas em Debate - v.10, n.1, p. 469-481, jan./abr. 2021 - ISSN 2238-8346 fracasso, produzidas por uma "verdade" construída socialmente, alicerçada em um discurso cruel de responsabilização ao professorado.

A Base Nacional Comum Curricular apresenta — de forma bem definida — a proposta de cinco unidades temáticas a serem desenvolvidas no ensino fundamental. São elas: os Números, a Álgebra, a Geometria, as Grandezas e Medidas, a Probabilidade e a Estatística. Todas as unidades são descritas e elucidam a preocupação com o que se pretende com cada uma dessas modalidades, para o que cada uma servirá no desenvolvimento das aprendizagens dos estudantes.

Durante a leitura do documento, percebe-se a imposição da BNCC quanto ao alcance dos alunos a essas competências e habilidades matemáticas, contudo, não se discute ou considera as condições necessárias ao trabalho do professor ou, mesmo (e não menos importante), a realidade desses estudantes.

Tanto as condições de trabalho dos professores, quanto a realidade em que os alunos se encontram são discussões relevantes para pensar quando essa comunidade recebe esse documento, principalmente tomando o cuidado de não tornar "comum” o que, de fato, é diferente e, assim, respeitar as diferenças.

O discurso que impera na área da Matemática, descrito pela BNCC, privilegia a concepção de uma Matemática única que deve ser inserida no mundo, no cotidiano e que, possivelmente, constituiu-se por um seleto grupo de intelectuais, só existindo no cotidiano porque extrapola os muros da escola. Ou seja, a Matemática só é produzida por aqueles que têm o poder do saber.

Passa-se a produzir a imagem de uma Matemática única e verdadeira, ainda que algumas pessoas partilhem do entendimento de que não existe uma verdade absoluta para as coisas, existem outras maneiras de contar, de medir, de classificar, além da Matemática difundida pelos currículos. Para Knijnik et al. (2013), as verdades acabam por legitimar certas práticas - e não outras - e, segundo as autoras, a produção dessas verdades ocorre dentro e fora do âmbito escolar.

A BNCC, ao indagar que, na área de Matemática, deve-se garantir aos alunos o “desenvolvimento de competências especificas”, limita o professor a seguir o que está descrito no documento, afinal (segundo a BNCC) esses são os conhecimentos necessários e indispensáveis para os educandos - subjetivando professores ao discurso da Base Nacional Comum Curricular.

Acrescenta-se a isso a unidade temática Probabilidade e Estatística, na qual “[ [...] todos os cidadãos precisam desenvolver habilidades para coletar, organizar, representar, interpretar e analisar dados de uma variedade de contextos [...]” (BRASIL, 2017, p. 274). Nela, observa-se que os estudos apontam para o papel importante desempenhado pela Estatística num contexto neoliberal, em pleno acordo com as regras de mercado, do mundo globalizado. 
Revista Educação e Políticas em Debate - v.10, n.1, p. 469-481, jan./abr. 2021 - ISSN 2238-8346

Os números existem em um conjunto de práticas culturais e organizam formas de pensar e executar. Necessitam ser objetivos, técnicos, precisos, com a ideia de dar a todos a mesma representação dos padrões. A fé nos números torna-se visível por meio de estatísticas, gráficos e fluxogramas. São dados aparentemente quantitativos que conferem autoridade a práticas de governo, pois dá a ideia de que foram organizadas em torno do cidadão e da democracia. A estatística, nesse contexto, dá estabilidade e fornece aparentemente uma análise dos fatos do mundo que aparentam possível controle (FÉLIX; FONSECA, p. 20, 2016).

Ao revelar as regularidades que a população apresenta, o conhecimento estatístico permite quantificar e manifestar fenômenos próprios, dando ao governo ciência dos desejos e das aspirações da população com base em premissas científicas, que vão implicar práticas de administração e de controle das pessoas, cujo objetivo é formar para o mercado. Competência última, agora sob responsabilidade do professorado.

\section{Considerações e apontamentos}

Este artigo discutiu as formas de subjetivação do professorado que ensina Matemática, com base no discurso da Base Nacional Comum Curricular. Ademais, apontouse para a relevância e a atualidade dessas reflexões. A pretensão das autoras foi problematizar os impactos na formação desse profissional para atuação no ensino fundamental regido por uma Base Nacional Curricular.

A questão que fica é referente a qual o lugar da diferença e das particularidades de cada sujeito e região nessa base curricular. Parece que, assim como exposto por Macedo (2016), há um evidente antagonismo entre as possibilidades de um currículo de formação e de avaliação universalizante e o discurso mascarado da Base a respeito de igualdade, respeito e equidade.

A BNCC, com relação à área da Matemática, traz as competências e os conteúdos evidenciando em seu discurso um foco em que prevalece o quantitativo, sendo este direcionado a um sistema de avaliação universal, englobando pouca preocupação com o processo qualitativo da aprendizagem.

Apesar de a BNCC sugerir o ensino de Matemática como uma ciência humana produzida por diferentes grupos sociais e culturais — o documento segue uma distribuição engessada de conteúdos e avaliações, um ensino hegemônico, um certo retrocesso que parecia ter sido superado no campo da Educação.

Por fim, reiterando a perspectiva da escola como um lugar de resistência e de lutas sociais, é preciso evidenciar que há, dentro do âmbito escolar, agentes (educadores e comunidade escolar, em geral) capazes de produzir seus próprios currículos, ou mesmo prezar pelas especificidades de 
Revista Educação e Políticas em Debate - v.10, n.1, p. 469-481, jan./abr. 2021 - ISSN 2238-8346 seu contexto social, ainda que inseridos em um currículo comum. Ainda há aqueles que buscam por uma escola com um currículo democrático, como o proposto por Apple e Beane (2001).

\section{REFERÊNCIAS}

ANPED e a BNCC: luta, resistência e negação. ANPEd, 2020. Disponível em: https://anped.org.br/content/anped-e-bncc-luta-resistencia-e-negacao. Acesso em: 24 set. 2020.

APPLE, M. W. Ideologia e Currículo. 3.ed. Porto Alegre: Artmed,2006.

APPLE, M. W. Reestruturação Educativa e Curricular e as agendas neoliberal e neoconserv adora: entrevista com Michael Apple. Currículo sem Fronteiras, v.1, n.1, p. 5-33, 2001.

APPLE, M. W.; BEANE, J. A. O argumento por escolas democráticas. In: APPLE, M. W.; BEANE, J. A. (orgs). Escolas Democráticas. 2. Ed. São Paulo: Cortez, 2001.

BRASIL. Base Nacional Comum Curricular (BNCC). Educação é a Base. Brasília, MEC/CONSED/UNDIME, 2017. Disponível em: <http://basenacionalcomum.mec.gov.br/>. Acesso em: 09 out. 2019.

FELIX, A. M. ; FONSECA, M. S. da . Práticas curriculares no RS: as (poli)técnicas de governamento. In: Loreto, A.B.; Fonseca, M.S.; Gil, R. L. (Org.). Escritas de professores experiências de formação. 1ed.Pelotas: Editora UFPel, 2016, v. 1, p. 11-28.

FONSECA, M. S.; RIOS, D. F. O livro didático como dispositivo pedagógico na formação de professores. In: MACHADO, C.C.; PINHO, D.S.; PEREIRA, E.C.; MAURELL, J.R.P.; SAGGIOMO, L.S.; ANTIQUEIRA, L.S. (Org.). Formação de professores e práticas educativas: olhares e reflexões. 1ed.Porto Alegre: Editora Casaletras, 2018.

FREIRE, P. Professoras sim, tia não; cartas para quem ousa ensinar. São Paulo - SP: Olho d’Água, 1997.

KNIJNIK, G. et al. Etnomatemática em movimento. $2^{\text {a }}$ edição. Belo Horizonte: Autêntica, 2013 (Coleção Tendências em Educação Matemática, 25).

MACEDO, E. Base Nacional Curricular Comum: a falsa oposição entre o conhecimento de fazer algo e conhecimento em si. Educação em Revista, Belo Horizonte, v.32, n.02, p. 45-67, Abr-Jun. 2016. DOI: https://doi.org/10.1590/0102-4698153052.

SACRISTÁN, J. G. Saberes e incertezas sobre o currículo. São Paulo: Penso, 2013.

SILVA, T. T. da. Documento de identidade - uma introdução às teorias de currículo. Belo Horizonte: Editora Autêntica, 1999.

VIEIRA, J.S., HYPÓLITO, A.L.M. Políticas curriculares, estandartização do conhecimento e ressignificação da aprendizagem. In: TURA, M.L.R., GARCIA, M.M.A. Currículo,

Políticas e Ação Docente. 1ed.Rio de Janeiro: EdUERJ, 2013, v. 1, p. 127-135. 